\title{
Vegetation chlorophyll estimates in the Amazon from multi-angle MODIS observations and canopy reflectance model
}

Thomas Hilker $^{1,2,{ }^{*}}$ (In Memoriam), Lênio Soares Galvão ${ }^{3}$, Luiz E. O. C. Aragão ${ }^{3}$, Yhasmin M. de Moura $^{3}$, Cibele H. do Amaral ${ }^{4}$, Alexei I. Lyapustin ${ }^{5}$, Jin $\mathrm{Wu}^{6,7}$, Loren P. Albert ${ }^{7}$, Marciel José Ferreira $^{8}$, Liana O. Anderson ${ }^{9}$, Victor A. H. F. dos Santos ${ }^{10}$, Neill Prohaska ${ }^{7}$, Edgard Tribuzy ${ }^{10}$, João Vitor Barbosa Ceron $^{10}$, Scott R. Saleska', Yujie Wang ${ }^{11}$, José Francisco de Carvalho Gonçalves $^{10}$, Raimundo Cosme de Oliveira Junior ${ }^{12}$, João Victor Figueiredo Cardoso Rodrigues ${ }^{8}$, Maquelle Neves Garcia ${ }^{10}$

1 University of Southampton, Department of Geography and Environment, Highfield Rd, Southampton SO17 1BJ, United Kingdom

${ }^{2}$ Oregon State University, College of Forestry, 231 Peavy Hall, Corvallis Oregon 97330, USA

${ }^{3}$ Instituto Nacional de Pesquisas Espaciais (INPE), Av. dos Astronautas, 1.758, Jd. da Granja, São José dos Campos - SP, 12227-010, Brazil

${ }^{4}$ Universidade Federal de Viçosa, Department of Forestry, Avenida Peter Henry Rolfs, s/n Campus Universitário, Viçosa - MG, 36570-900, Brazil

${ }^{5}$ NASA Goddard Space Flight Center, 8800 Greenbelt Road, Greenbelt, MD 20771

${ }^{6}$ Environmental \& Climate Sciences Department, Brookhaven National Lab, Upton, New York, NY, 11973

${ }^{7}$ University of Arizona, Department of Ecology and Evolutionary Biology, Biosciences West 310, Tucson, AZ 85721

${ }^{8}$ Universidade Federal do Amazonas, Depto. de Ciências Florestais, Avenida General Rodrigo Octávio, 6200 - Coroado I, Manaus - AM, 69077-000, Brazil 
${ }^{9}$ Centro Nacional de Monitoramento e Alertas de Desastres Naturais (CEMADEN) Estrada Dr. Altino Bondensan, 500 - Coqueiro, São José dos Campos - SP, 12247-016, Brazil

${ }^{10}$ Instituto Nacional de Pesquisas da Amazônia (INPA), Av. André Araújo, 2936 - Petrópolis, Manaus - AM, 69067- 375, Brazil

11 Joint Center for Earth System Technology, University of Maryland Baltimore County, Baltimore MD

${ }^{12}$ Empresa Brasileira de Pesquisa Agropecuária (EMBRAPA), Centro de Pesquisa Agroflorestal da Amazônia Oriental, 66095100 - Belém, PA - Brasil

Corresponding author: lenio.galvao@inpe.br 


\section{Abstract.}

As a preparatory study for future hyperspectral missions that can measure canopy chemistry, we introduce a novel approach to investigate whether multi-angle Moderate Resolution Imaging Spectroradiometer (MODIS) data can be used to generate a preliminary database with long-term estimates of chlorophyll. MODIS monthly chlorophyll estimates between 2000 and 2015, derived from a fully coupled canopy reflectance model (ProSAIL), were inspected for consistency with eddy covariance fluxes, tower-based hyperspectral images and chlorophyll measurements. MODIS chlorophyll estimates from the inverse model showed strong seasonal variations across two flux-tower sites in central and eastern Amazon. Marked increases in chlorophyll concentrations were observed during the early dry season. Remotely sensed chlorophyll concentrations were correlated to field measurements $\left(r^{2}=0.73\right.$ and $r^{2}=$ 0.98) but the data deviated from the $1: 1$ line with root mean square errors (RMSE) ranging from $0.355 \mu \mathrm{g} \mathrm{cm}^{-2}$ (Tapajós tower) to $0.470 \mu \mathrm{g} \mathrm{cm}$ (Manaus tower). The chlorophyll estimates were consistent with flux tower measurements of photosynthetically active radiation (PAR) and net ecosystem productivity (NEP). We also applied ProSAlL to mono-angle hyperspectral observations from a camera installed on a tower to scale modeled chlorophyll pigments to MODIS observations $\left(r^{2}=0.73\right)$. Chlorophyll pigment concentrations $\left(\mathrm{Chl}_{\mathrm{A}+\mathrm{B}}\right)$ were correlated to changes in the amount of young and mature leaf area per month $\left(0.59 \leq r^{2} \leq 0.64\right)$. Increases in MODIS observed $\mathrm{Chl}_{\mathrm{A}+\mathrm{B}}$ were preceded by increased PAR during the dry season $\left(0.61 \leq \mathrm{r}^{2} \leq 0.62\right)$ and followed by changes in net carbon uptake. We conclude that, at these two sites, changes in LAI, coupled with changes in leaf chlorophyll, are comparable with seasonality of plant productivity. Our results allowed the preliminary development of a 15-year time series of 
chlorophyll estimates over the Amazon to support canopy chemistry studies using future hyperspectral sensors.

Keywords: Chlorophyll; phenology; Amazon; MODIS; hyperspectral; ProSAIL; multi-angular.

\section{Introduction}

Chlorophyll-based photosynthesis mediates up to $90 \%$ of the gas exchange between the terrestrial biosphere and the atmosphere (Ozanne et al., 2003). However, in tropical regions, the controls on photosynthetic seasonality are less well understood than in temperate zones (Cleland et al., 2007; Wu et al., 2016). In Amazonia, in-situ observations from eddy-flux towers (Hutyra et al., 2007; Restrepo-Coupe et al., 2013; Saleska et al., 2003) and field data (Doughty and Goulden, 2008; Zhang et al., 2010) suggest seasonal variations in gross carbon uptake also in evergreen vegetation. The processes driving these changes are only poorly represented in earth system models. In the absence of water limitation, oscillations in photosynthetic fluxes of evergreen tropical forests are likely a consequence of allocation of resources to growth of new leaves (Restrepo-Coupe et al., 2013; Wu et al., 2016). In equatorial forests, leaf flushing is correlated with increased light availability during the dry season while water supply is maintained through deep root systems (Nepstad et al., 1994). In contrast, more water limited environments of southern Amazonia have shown photosynthesis decline during the dry season, likely in response to depletion of soil water (Guan et al., 2015).

Frequent satellite observations of vegetation biochemistry and leaf area may provide clues necessary to fully understand the seasonal rhythm of ecosystem metabolism. However, remote 
sensing of tropical regions has proven challenging and resulted in an extensive debate over sunlight and precipitation mediated changes in tropical regions (Bi et al., 2015; Morton et al., 2014; Samanta et al., 2012). Some studies (Huete et al., 2006; Myneni et al., 2007; Zhou et al., 2014) have reported widespread and large seasonal swings between dry and wet season, whereas others have suggested no observational evidence for changes in tropical vegetation (Atkinson et al., 2011; Morton et al., 2014). The discrepancies can in part be attributed to errors in the estimation of atmospheric aerosol loadings and deficiencies in cloud screening (Hilker et al., 2015).

New scaling approaches in combination with comprehensive field studies may help resolve some of these uncertainties and obtain a more biophysical understanding of the climatic and biological interactions during dry and wet periods. Most remote sensing time series use vegetation indices (VIs) for assessing vegetation responses to climate variables. While based on well-described physical principles, VIs are fundamentally empirical, because they are related to plant physiological traits, but do not explicitly model leaf-to-canopy radiative transfer. VIderived vegetation greenness is therefore dependent on soil and background effects, canopy structure and the view-illumination geometry (Galvão et al., 2013; Huete et al., 2006). Furthermore, Vls saturate in high biomass canopies (Moura et al., 2015).

Complementary to evidence of greenness derived from Vls, canopy reflectance (CR) models may provide new insights into seasonal variations of tropical vegetation. Canopy reflectance models couple radiative transfer theory with leaf optical models to simulate reflectance and transmittance of light through a canopy as a function of its constituents (Jacquemoud et al., 2009). When inverted, these models can provide estimates of biophysical quantities in an 
analytical fashion so that derived products are better scale-able in space and time. While CR models have existed for some time, their use over large areas has been hampered by the availability of suitable reflectance data. First, retrieval of biochemical estimates from inverse CR models depends on the quality of radiometric information in the visible and near infrared (NIR) spectrum and on the accuracy of atmospheric correction and cloud screening. Currently, orbital imaging spectrometers or hyperspectral sensors to measure canopy chemistry with $30 \mathrm{~m}$ spatial resolution and high signal-to-noise are not available for Earth observation. Second, inverse modeling requires at least as many independent spectral observations as there are unknowns. Alternatively, these independent measurements can be obtained from multi-angle and multispectral observations. In this context, recently developed data processing techniques, such as the Multi-Angle Implementation of Atmospheric Correction Algorithm (MAIAC, Lyapustin et al., 2012), provide new opportunities for large scale model inversions by exploiting the multi-angle capacity of the Moderate Resolution Imaging Spectroradiometer (MODIS).

As a preparatory study for the Environmental Mapping and Analysis (EnMAP) planned for 2019 (Guanter et al., 2015), we investigate whether MODIS (MAIAC) multi-angle observations can be utilized to characterize changes in vegetation chlorophyll from an inverted canopy reflectance model. The idea is to compose a preliminary temporal database of vegetation chlorophyll over the Amazon that can serve as reference for future studies using hyperspectral sensors. We utilized ProSAIL, a fully coupled, canopy reflectance model of plant biophysical properties (Jacquemoud et al., 2009) that is among the most widely used and validated models in temperate and dense, tropical ecosystems (Galvão et al., 2013; Zhang et al., 2010). In Brazil, we focused our analysis on a large area of the Amazon (1000 x $1000 \mathrm{~km})$ and on two flux-tower 
field stations (Manaus and Tapajós). MODIS derived estimates between 2000 and 2015 were inspected for consistency using eddy covariance derived fluxes, tower-based hyperspectral chlorophyll estimates, and field chlorophyll measurements to analyze seasonal patterns of pigment concentrations. By combining canopy reflectance model (ProSAIL) with multi-angle and directional observations from MODIS, the current approach is novel in providing an alternative to the use of empirical VIs to derive pigments and assess vegetation seasonality in the Amazon. It was also adapted to mono-angle observations acquired by a tower-mounted hyperspectral camera in Tapajós.

\section{Methods}

\subsection{Study area}

The study area has 1000 × $1000 \mathrm{~km}$ and includes the cities of Manaus and Santarém (Figure 1). We also utilized data from two forest sites in the Brazilian Amazon: the Tapajós National Forest (k67-tower) in the state of Pará $\left(2.85^{\circ} \mathrm{S}, 54.97^{\circ} \mathrm{W}\right)$ and the Reserva Cuieiras (k34-tower) in the state of Amazonas $\left(2.61^{\circ} \mathrm{S} 60.21^{\circ} \mathrm{W}\right)$ (Figure 1).

The sites span a gradient in precipitation and dry season length. The Tapajós forest is a moist primary forest with a mean precipitation of $2000 \mathrm{~mm}$ year $^{-1}$ and an average dry season length of 4.7 months (Hutyra et al., 2007). The Reserva Cuieiras is a primary rain forest with an annual precipitation of $2600 \mathrm{~mm}$ and a dry season length of 2.4 months (Wu et al., 2016). Ground and eddy flux measurements at both sites have been collected since 1999 as part of the Large-Scale Biosphere-Atmosphere Experiment in Amazonia (LBA). 


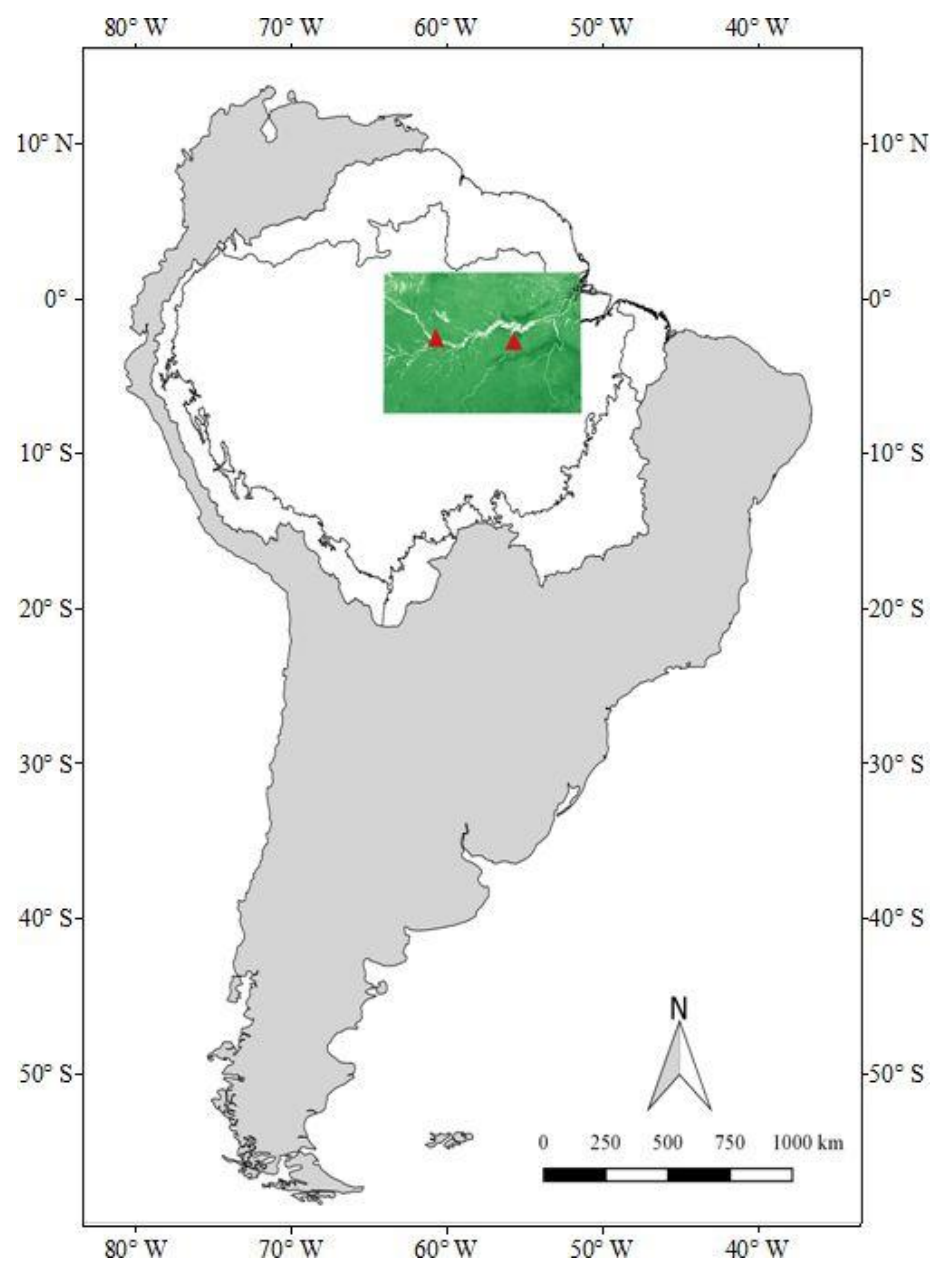

Fig. 1. Location of the study area in the Brazilian Amazon. The location of the k34 (Manaus) and k67 (Tapajós) towers is indicated by red triangles on the left and right sides of the image, respectively.

\subsection{Ground based and tower based measurements}

In the Tapajós (k67) site, Eddy covariance (EC) estimates of net ecosystem productivity (NEP) and top-of-canopy photosynthetically active radiation (PAR) were collected between April 2001 and January 2006 (Hutyra et al., 2007). The estimates were downloaded as monthly 
daytime averages from the Oak Ridge National Laboratory's Distributed Active Archive Center. The LBA project also provided field measurements of leaf area index (LAI) at k67 acquired between January and December 2004 (not all months were observed) (Costa and Cohen, 2013).

Leaf level measurements of vegetation chlorophyll were collected within the flux tower footprint on November 13-15, 2012. Using tree climbing to harvest branches from the upper canopy, the leaves were cut and immediately placed in liquid nitrogen. The absorbance at 663 $\mathrm{nm}$ and $647 \mathrm{~nm}$ of the supernatent was used to estimate chlorophyll- $a$ and chlorophyll- $b$ concentrations following the protocol of Lichtenthaler (1987). From five common canopy tree species at Tapajós k67 site, 53 leaves were sampled in situ from both sunlit (canopy top) and deeply shade environments (5-10 meters depth within the canopy). The leaves were also classified by three different leaf age classes (young: leaf age $<2$ months old; mature: $3-6$ months old; old: $>6$ months old), with 1-3 replicates for each leaf age class.

In order to test the ability to scale ground measurements of chlorophyll, we also utilized data from the SOC-710 portable hyperspectral imaging system (Surface Optics Corporation, San Diego, CA, US) that was mounted at a height of $61 \mathrm{~m}$ on the k67 eddy covariance tower. The SOC-710 is a 12-bit camera (low-noise silicon-based CCD) with spectral resolution of $4.7 \mathrm{~nm}$. It operates in normal lighting conditions with variable exposure times and gain. The camera acquires data from 385 to $1050 \mathrm{~nm}$ in 128 spectral bands. Seventeen hyperspectral SOC-710 images were carefully selected and screened for data quality and clear sky conditions between July 27 and October 29, 2012. Reflectance measurements were calibrated using a Teflon panel. Images were acquired at an angle of $45^{\circ}$ off-nadir around solar noon to minimize shading differences within the canopy. 
In the Manaus (k34) site, NEP and PAR for the Cueiras Reserve were available between 1999 and 2006 as monthly averages. Field measurements of vegetation chlorophyll were obtained within the flux tower footprint between April and November of 2015. 203 leaves were sampled in situ within the tree canopies and classified by species, leaf age (young, mature, old) and light environment (sunlit/shaded and understorey). Leaves were cut and immediately kept on ice until laboratory analysis. The absorbance at $663 \mathrm{~nm}(\mathrm{Chl} a)$ and $645 \mathrm{~nm}(\mathrm{Chl} b)$ was measured using the Ultrospec 2100 pro UV/visible (Amersham, Biosciences, Cambridge, UK).

\subsection{MODIS observations}

We obtained MODIS (MAIAC) observations for a $1000 \times 1000 \mathrm{~km}$ area spanning both tower sites between 2000 and 2015. Detailed descriptions of the MAIAC algorithm and of the assessment of errors and uncertainties are provided by Lyapustin et al. (2012) and Hilker et al. (2015), respectively. We utilized daily, $1 \mathrm{~km}$ surface reflectance products of MODIS bands 1-12 together with the sun-observer geometry of the individual observations as input data to ProSAIL.

The MAIAC quality information was used. Data were quality screened using the MAIAC quality flags in order to filter clouds or observations with high aerosol content. Only high quality pixels were selected. 


\subsection{Inversion of the ProSAIL canopy model from MODIS and hyperspectral tower data}

ProSAIL is a combination of the PROSPECT leaf optical properties model and the SAIL canopy bidirectional reflectance model (Jacquemoud et al., 2009). Coupling of PROSPECT and SAIL as implemented in ProSAIL allows the assessment of canopy biochemistry through model inversion using multi-angle reflectance observations. Different optimization techniques are available. In this study, we used a modified Levenberg-Marquardt algorithm (implemented in the 'minpack' c-library) to calculate the Jacobian matrix from forward-difference approximation (Moré et al., 1980).

Leaf area was not retrieved from PROSAIL model inversion, but instead estimated as a linear function of anisotropy of the Enhanced Vegetation Index (EVI) calculated from forward and backscatter reflectance and validated against field data, following the approach by Moura et al. (2015). Briefly, canopy structure affects the directional scattering of light and this scattering is observable from multi-angle observations. We utilized the RTLS BRDF model (Roujean et al., 1992) to derive forward and backscatter reflectance of the EVI and obtained LAI as linear function of the difference between them.

The estimated LAI values were then used to constrain the model inversion and retrieve canopy biochemistry (model unknowns: Chlorophyll ${ }_{A+B}$, Carotenoids, Canopy water, Nitrogen) based on daily directional MODIS reflectance observed within that month. While our inversion approach yields all model unknowns as output, we focused our analysis on the chlorophyll 
estimates. The estimates prior to May 2002 were solely based on MODIS/Terra data and, after this date, on Terra and Aqua. To reduce the number of necessary inversions, we first identified groups of pixels of similar nadir reflectance and leaf area (Figure 2). This was accomplished through normalizing the directional reflectance of MODIS bands 1-12 to a view zenith angle (VZA) of $0^{\circ}$ and solar zenith angle (SZA) of $45^{\circ}$, using the Ross-Thick Li-Sparse (RTLS) kernels (Roujean et al., 1992) provided in MAIAC. The BRDF normalization was applied only to identify groups of pixels with similar reflectance characteristics. The model inversion itself was still run using the observed, directional reflectance. Second, a hierarchical clustering algorithm was applied to calculate similarity and dissimilarity of all pixels and across all reflectance bands using standardized z-scores. Finally, a subset of 100 pixels was randomly selected from within each group and from as wide a range of observations angles as possible to run the inverse model for a given month based on MAIAC directional reflectance and estimated LAI. Since ProSAIL accounts for the sun-viewing geometry, the use of directional reflectance therefore maximizes the number of independent observations. 


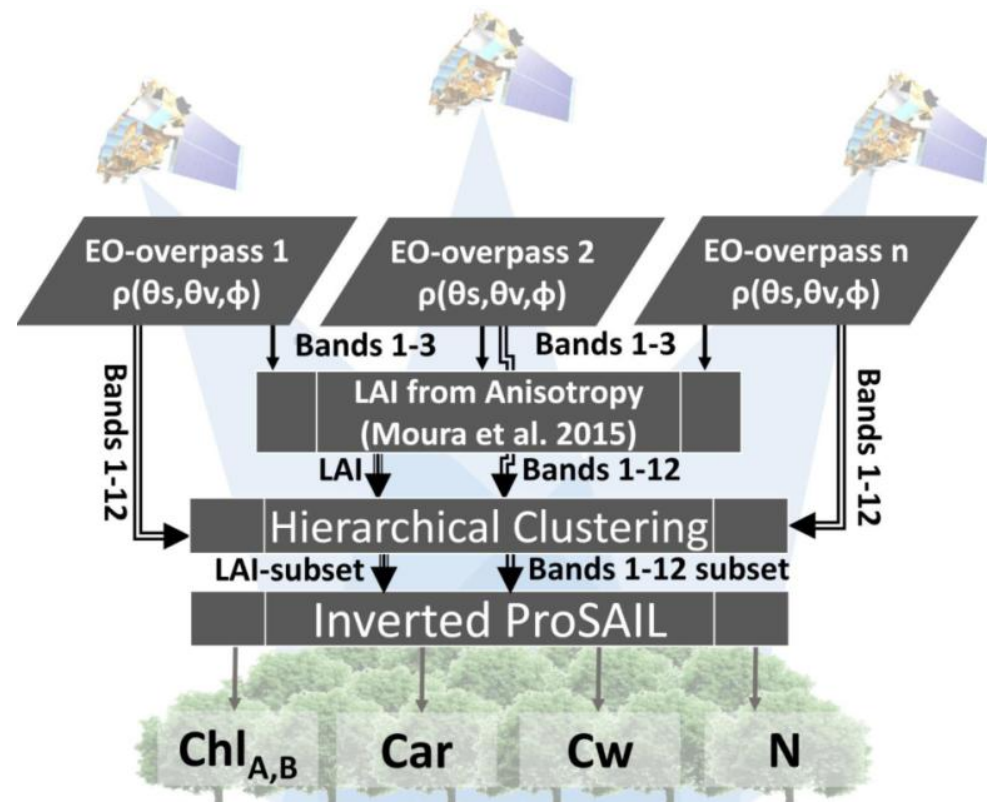

Fig. 2. Flux diagram of the ProSAIL inversion for a given month. Multiple Earth observation (EO) MODIS overpasses were combined to obtain leaf Area Index (LAI) from multi-angle scattering (anisotropy) of the MODIS Enhanced Vegetation Index (EVI) bands. Estimates of LAI were combined with MODIS reflectance $(\rho)$ of bands 1-12 to invert the ProSAIL model and calculate chlorophyll $\left(\mathrm{ChI}_{\mathrm{A}, \mathrm{B}}\right)$, carotenoids (Car), canopy water $(\mathrm{CW})$ and nitrogen $(\mathrm{N})$. A hierarchical clustering algorithm was used to limit the number of inversions necessary across the study scene. $\theta \mathrm{s}, \theta \mathrm{v}$ and $\varphi$ are the solar zenith angle, view zenith angle and relative azimuth angle, respectively.

Estimates of chlorophyll were also computed from the SOC-710 hyperspectral camera images using all 128 bands. Similar to the process described for MODIS, pixel observations were grouped into areas with similar reflectance values using hierarchical clustering, assuming a LAI of $6.0 \mathrm{~m}^{2} \mathrm{~m}^{-2}$ (Costa and Cohen, 2013; Wu et al., 2016). No multi-angular observations were 
available from the tower-based camera. Therefore, chlorophyll estimates were derived using reflectance data clustered for similar shade fractions instead. Differences in canopy shading were obtained using the sequential maximum angle convex cone (SMACC) algorithm (Gruninger et al., 2004) to determine spectral endmembers and the abundance of canopy shading on a per pixel basis for each date.

Finally, independent estimates of measurement uncertainties are difficult to acquire at $1 \mathrm{~km}$ spatial resolution. In this study, we obtained uncertainties of surface reflectance from day to day reflectance variability in all 12 bands for all months within the observation period (Hilker et al., 2012). Error propagation and uncertainties in remotely sensed vegetation chlorophyll were then inferred by running repeated model inversions $(n=100)$ and randomly varying input surface reflectance by the observed intra-monthly range of MODIS reflectance values.

\section{Results}

The strong linear relationship between field-measured LAI and LAI acquired from MODIS anisotropy at the Tapajós site confirmed the ability of MODIS anisotropy to describe seasonal changes in vegetation leaf area (Figure 3). The modelled LAl underestimated the field observations by about $0.3 \mathrm{~m}^{2} \mathrm{~m}^{-2}$. Part of the bias in LAl may stem from the differences in footprint size of the two measurement types.

ProSAIL modelled vegetation chlorophyll $\left(\mathrm{Ch}_{\mathrm{A}+B}\right)$ from multi-angle MODIS observations varied by up to $15 \mu \mathrm{g} \mathrm{cm}^{-2}$ seasonally. Wet season (February 2004) $\mathrm{Ch}_{\mathrm{A}+\mathrm{B}}$ averaged about 35.0 $\mu \mathrm{cm}^{-2}$ across the study area (Figure 4A), whereas the end-of-dry season (October 2004) mean was about $38.3 \mathrm{mg} \mathrm{cm}^{-2}$ (Figure 4B), which represented a $10 \%$ change in mean $\mathrm{Chl}$ 
concentration. Data gaps were more common during the wet season than during the dry period due to extensive cloud cover.

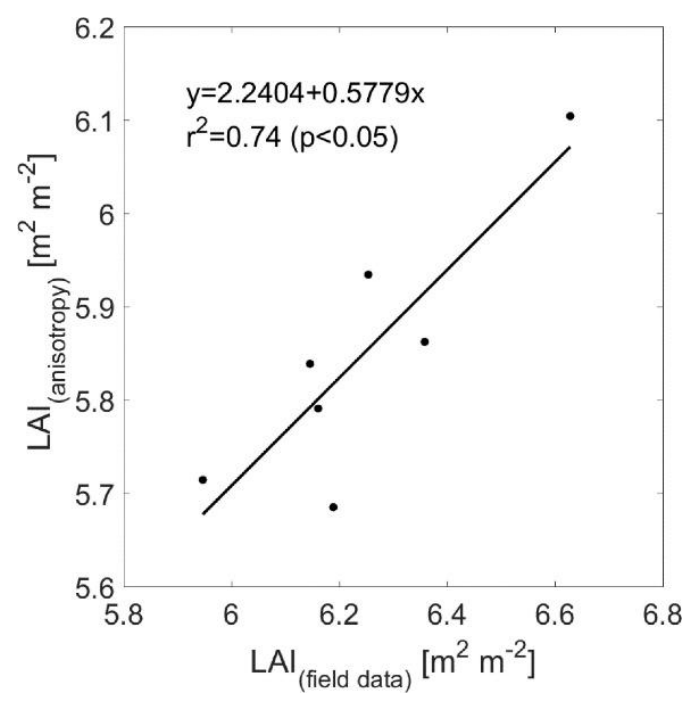

Fig. 3. Relationship between field measurements of LAI and LAl modelled as a function of MODIS anisotropy. Field and MODIS observations were available for January, May, June, July, August, October and November of 2004. MODIS data are shown for the corresponding time intervals. The root mean square error (RMSE) is $0.08 \mathrm{~m}^{2} \mathrm{~m}^{-2}$ and the statistical significance level of the correlation is 0.05 . 
A

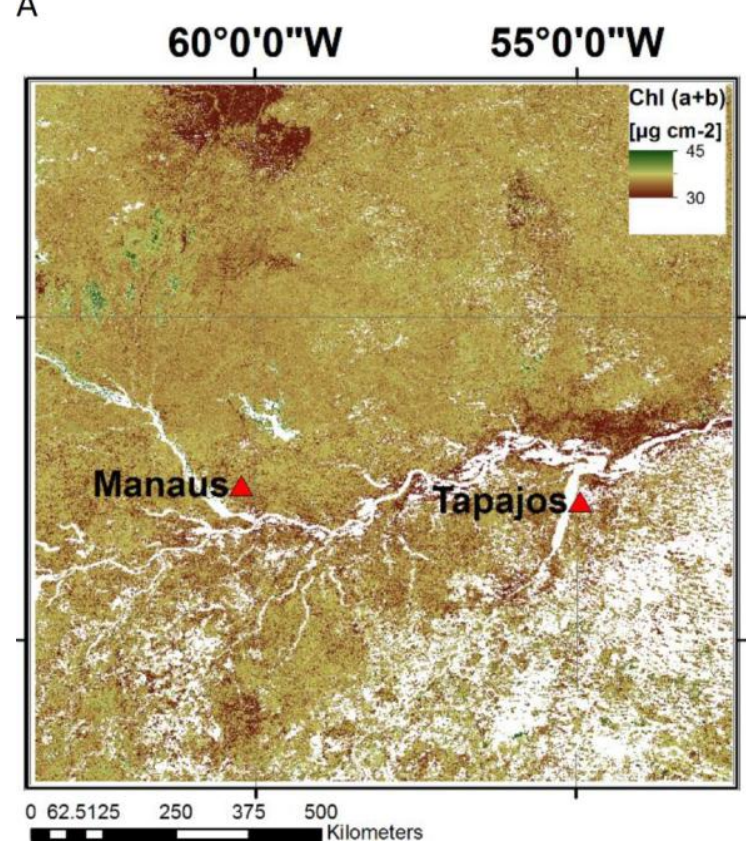

B

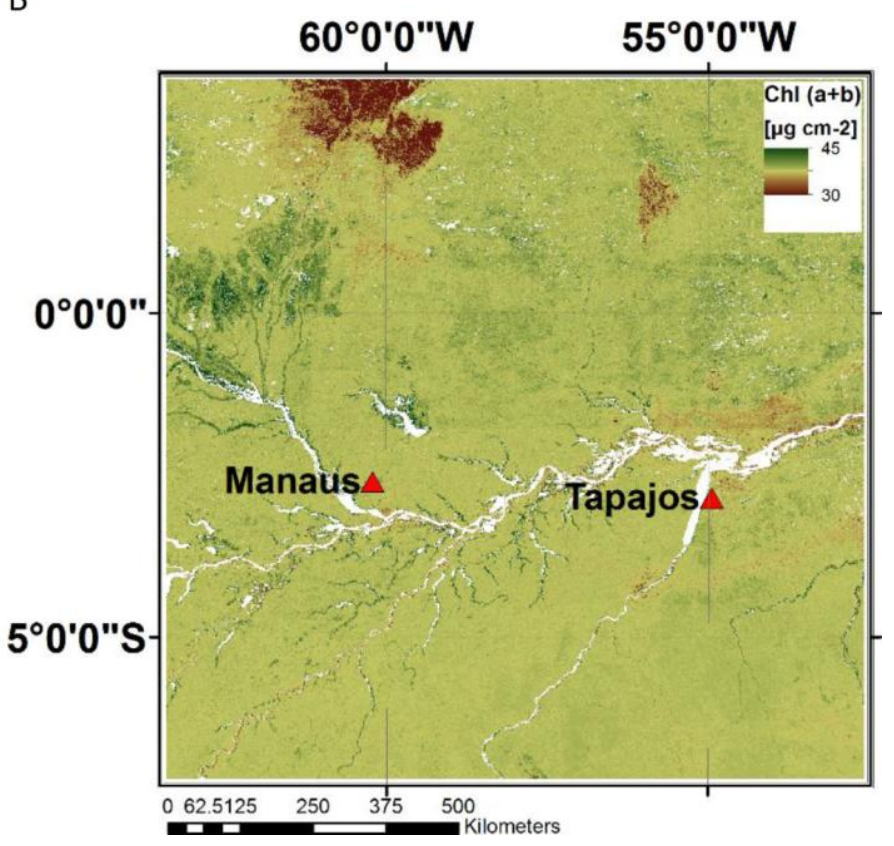

Fig. 4. Seasonal variation in ProSAIL derived concentrations of vegetation chlorophyll $\left(\mathrm{Chl}_{\mathrm{A}+\mathrm{B}}\right)$ in February (A) and October (B) 2004. The location of the k34 (Manaus) and k67 (Tapajós) towers is illustrated as red triangles.

Both sites exhibited clear seasonal variations in chlorophyll concentrations with values ranging between 30 and $40 \mu \mathrm{cm}^{-2}$ (Figures $5 \mathrm{~A}$ and $5 \mathrm{~B}$ ). The mean error of chlorophyll estimates was $1.04 \mu \mathrm{g} \mathrm{cm}^{-2}$ at Manaus and $1.10 \mu \mathrm{g} \mathrm{cm}^{-2}$ at Tapajós. The seasonal amplitude in chlorophyll was notably larger at Tapajós $\left(8 \mu \mathrm{g} \mathrm{cm}{ }^{-2}\right.$ per year at $k 67 \mathrm{vs.} 4 \mu \mathrm{g} \mathrm{cm}{ }^{-2}$ per year at k34), which corresponds well with the drier climate and the longer dry season encountered in this part of the basin. 
A

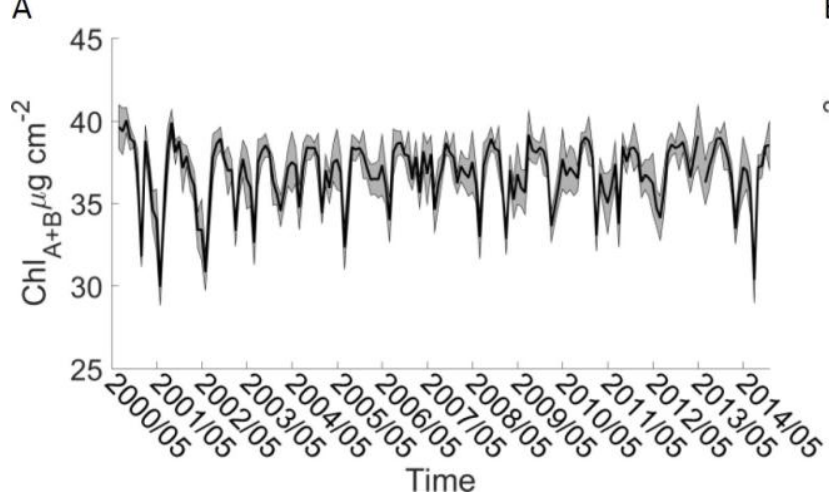

B

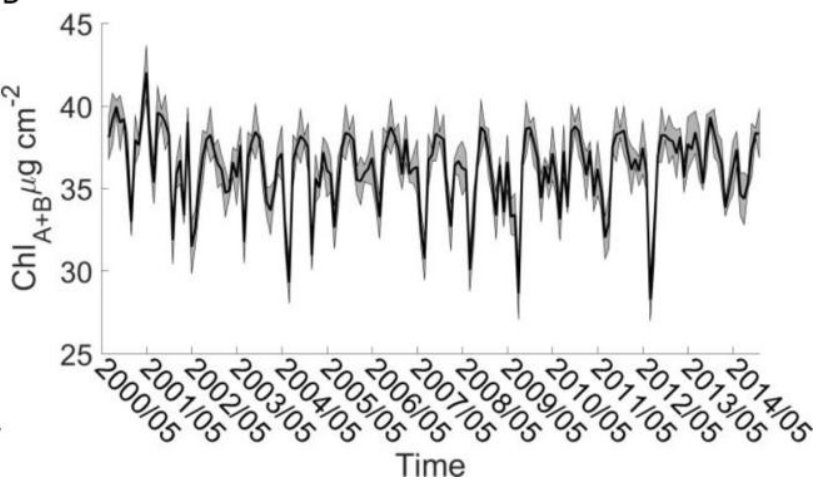

Fig. 5. Time series of ProSAIL derived $\mathrm{Chl}_{A+B}$ observed at Manaus $(\mathrm{A})$ and Tapajós $(B)$ between 2000 and 2014 ( $3 \mathrm{~km}$ radius around the tower). The gray area represents the estimated uncertainty range calculated as standard deviation of the propagated range of reflectance observed within a month.

Figure $6 \mathrm{~A}$ shows a true color composite obtained by the hyperspectral camera in August 5, 2012, with the SOC-710 bands centered at $666 \mathrm{~nm}$ (red), $563 \mathrm{~nm}$ (green) and $487 \mathrm{~nm}$ (blue). The main species encountered within the camera footprint were indicated. From the SMACC analysis, we considered "shaded" pixels as those with more than 0.6 shadow fraction, while "sunlit" pixels were defined as those with less than 0.3 shadow fraction (Figure 6B). Only regions with more than $60 \%$ shading were used. Hierarchical clustering identified 598 groups of pixels with similar reflectance. Excluding the shaded portions of the scene, modelled chlorophyll estimates between the species varied from 32 to $50 \mu \mathrm{g} \mathrm{cm}^{-2}$. Manilkara huberi showed the highest mean $\mathrm{Chl}_{\mathrm{A}+\mathrm{B}}$ concentrations $\left(46.8 \mu \mathrm{g} \mathrm{cm}^{-2}\right)$. Mean values for Erisma uncinatum and Chamaecrista xinguensis were $45.5 \mu \mathrm{g} \mathrm{cm}^{-2}$ and $43.4 \mu \mathrm{g} \mathrm{cm}^{-2}$, respectively (Figure 6C). 
Hyperspectral camera observations closely matched in rank chlorophyll measurements obtained in the field (Figure 7A). A highly significant linear relationship $\left(r^{2}=0.98, p<0.05\right)$ was observed between the field samples, categorized into species, sunlit and shaded vegetation, and the camera observations that best matched the sampling date (September 25, 2012). The field observations were averaged by species and shade/sun status. The total number of samples presented in Figure 7A $(n=4)$ appears small, but results are average values based on all 53 field observations. We also investigated the potential to scale tower observations in time by matching the sequence of SOC-710 images available at k67 between July and September to the corresponding MODIS overpasses. The results confirmed a highly significant linear correlation $\left(r^{2}=0.73, p<0.05\right)$ also in the temporal domain (Figure 7B). The relationship was systematically biased, as camera based $\mathrm{Chl}_{\mathrm{A}+\mathrm{B}}$ varied between $42 \mu \mathrm{g} \mathrm{cm}{ }^{-2}$ and $52 \mu \mathrm{g} \mathrm{cm}^{-2}$, whereas seasonal changes observed by MODIS ranged only between $36 \mu \mathrm{g} \mathrm{cm}$ and $38 \mu \mathrm{cm}^{-2}$, possibly due to differences in shadow fractions resulting from the very different pixel size observed by the two instruments. Observations made at the Tapajós site were confirmed also for Manaus (Figure 8). At k34, no tower-mounted hyperspectral camera was available. However, chlorophyll observations acquired repeatedly over seven months provided an opportunity to relate field measurements to MODIS observations directly. While the ProSAIL applied to tower hyperspectral data underestimated the field measured chlorophyll at k67 (Figure 7b), it overestimated this constituent when using MODIS data at k34 (Figure 8). Differences in offsets observed in Figures $6 \mathrm{~b}$ and 7 may be explained by the distinct footprint sizes of the two measurement types (tower and satellite) and by the difficulties to model shading on each dataset. 

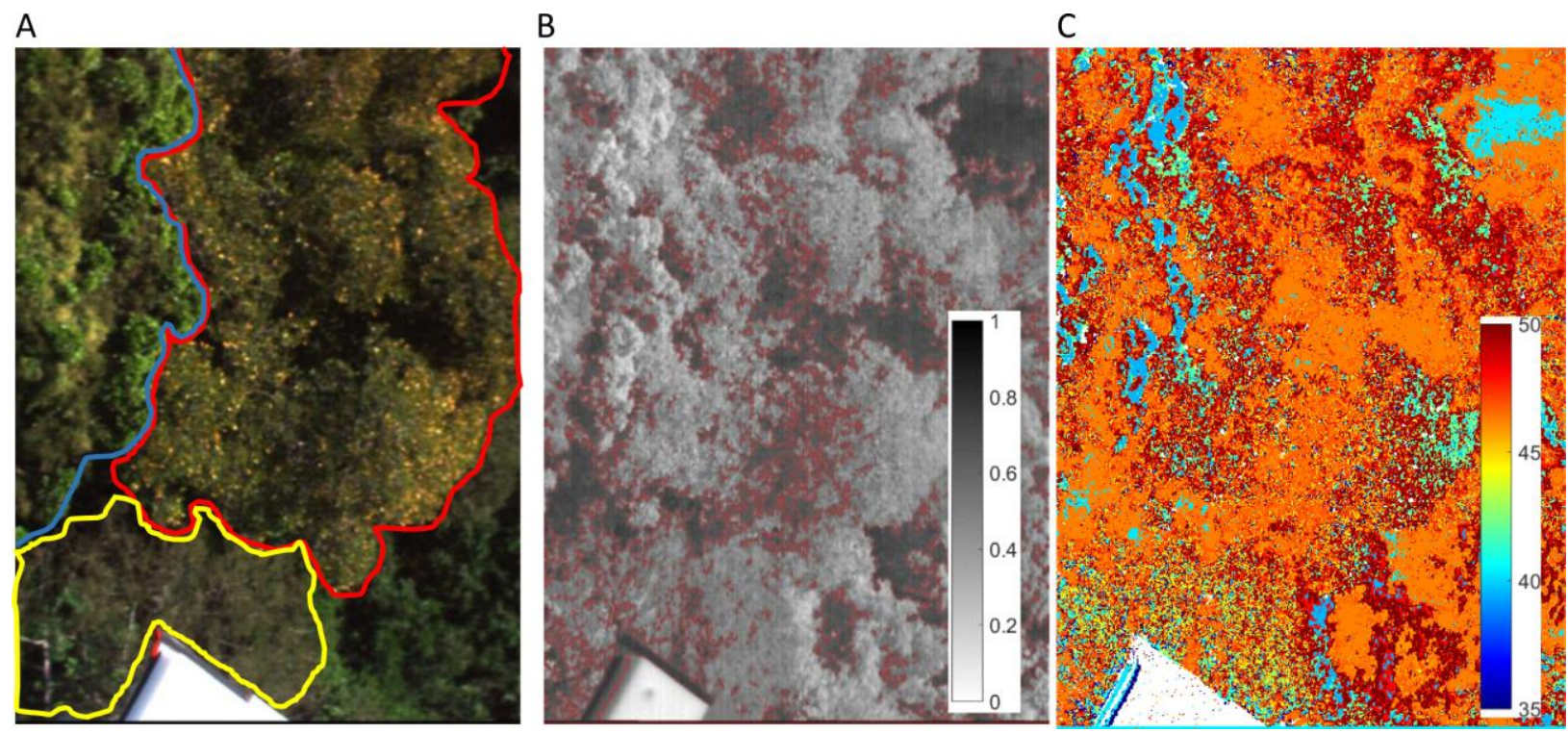

Fig. 6. (A) Illustration of SOC-710 hyperspectral imagery in a true color composite. The three main species delineated in the camera footprint are Manilkara huberi (in red), Erisma uncinatum (in blue) and Chamaecrista xinguensis (in yellow). (B) Corresponding shadow fraction endmember modelled using the SMACC algorithm; and (C) $\mathrm{Chl}_{\mathrm{A}+\mathrm{B}}$ estimates $\left(\mu \mathrm{gm}^{-2}\right.$ ) obtained from ProSAIL. The calibration panel is visible at the bottom of the image (excluded from analysis). The red polygons in (B) represent areas with more than $60 \%$ shading. 
A

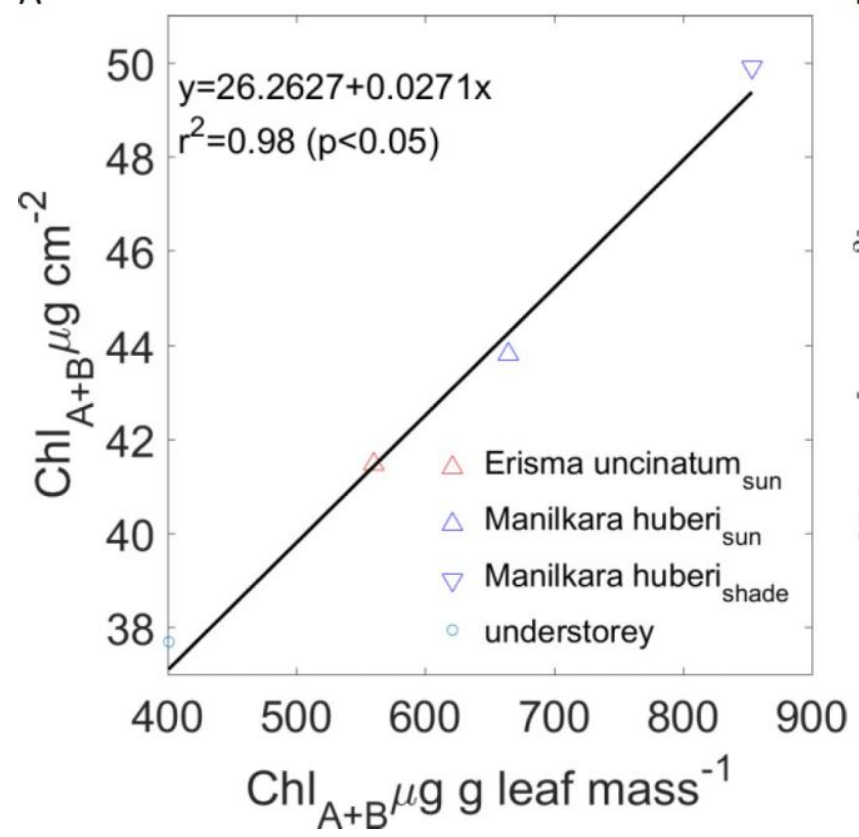

B

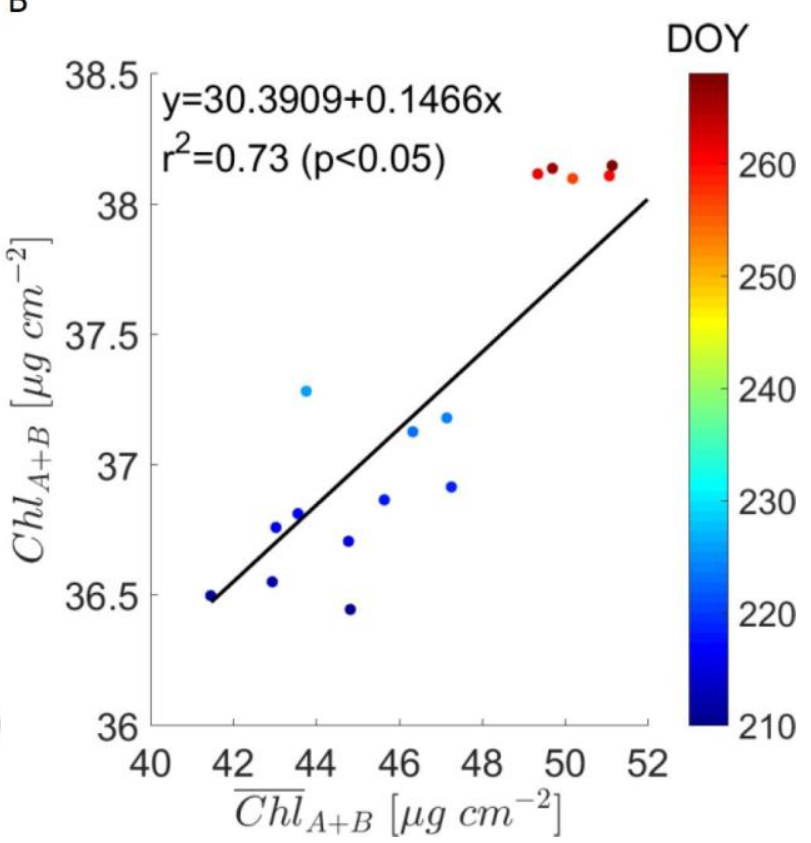

Fig. 7. (A) Relationship between field measured vegetation chlorophyll at k67, categorized by species, sunlit and shaded leaves (average of 53 observations), and modelled $\mathrm{Chl}_{\mathrm{A}+\mathrm{B}}$ using the camera image that best matched the field sampling date (September 25, 2012). Relationship between $\mathrm{k} 67$ tower-based $\mathrm{Chl}_{\mathrm{A}+\mathrm{B}}$ using the full time series of camera observations (x-axis) between July 27 and October 29 and $\mathrm{Chl}_{\mathrm{A}+\mathrm{B}}$ estimates obtained from the corresponding MODIS overpasses (y-axis). The RMSE is $0.355 \mu \mathrm{g} \mathrm{cm}^{-2}$.

MODIS derived $\mathrm{Chl}_{A+B}$ estimates were closely related to incoming PAR measured at the top of the k34 and k67 flux towers between 2000 and 2006 (Figures 8A and 8B). Values shown are daytime monthly averages. We included a one-month lag in our analysis to allow for a response time of the chlorophyll build-up. $\mathrm{ChI}_{\mathrm{A}+\mathrm{B}}$ values from a given month were related to PAR values from the previous month. 


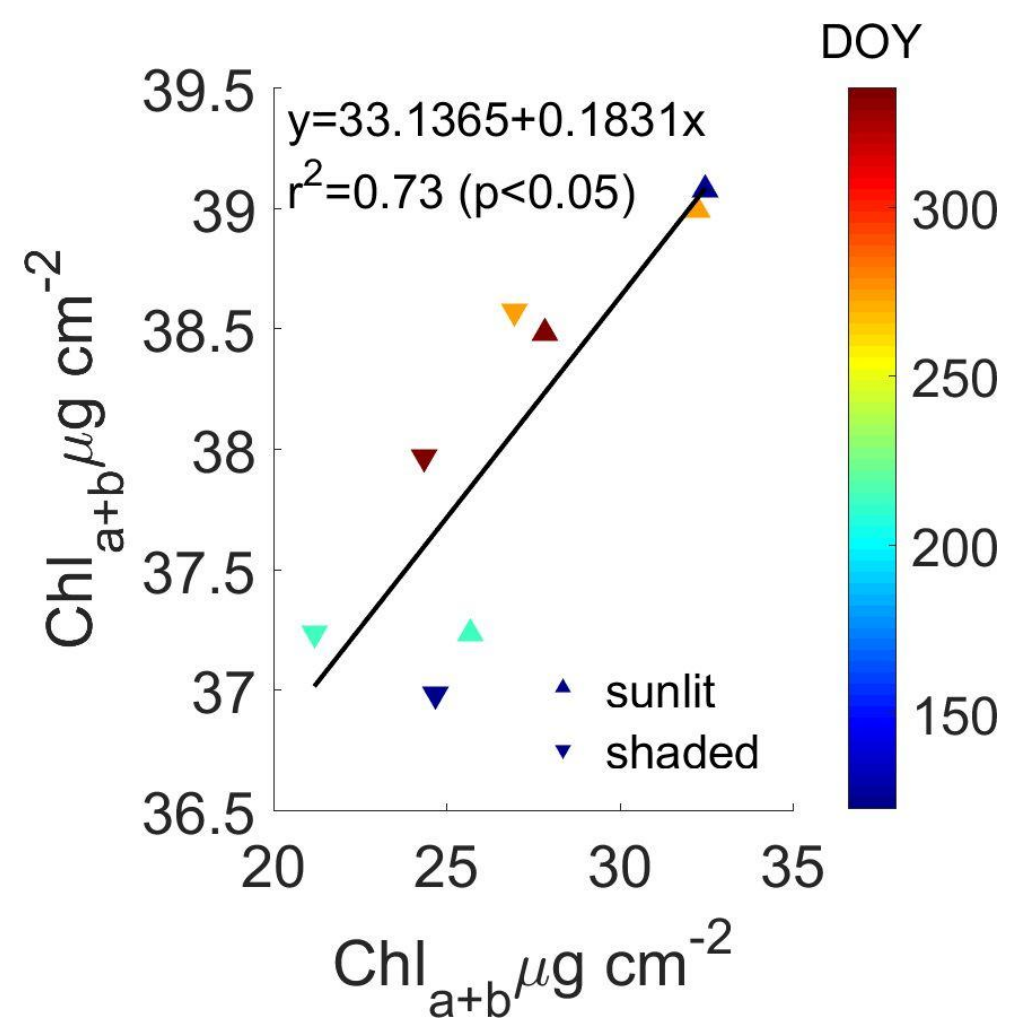

Fig. 8. Relationship between vegetation chlorophyll measured at k34, categorized into sunlit and shaded foliage, and corresponding MODIS $\mathrm{Chl}_{\mathrm{A}+\mathrm{B}}$ ( $\mathrm{y}$-axis) acquired over the same month. The acquisition dates are color coded by day of year (DOY). The RMSE is $0.470 \mu \mathrm{gm}^{-2}$ 
A

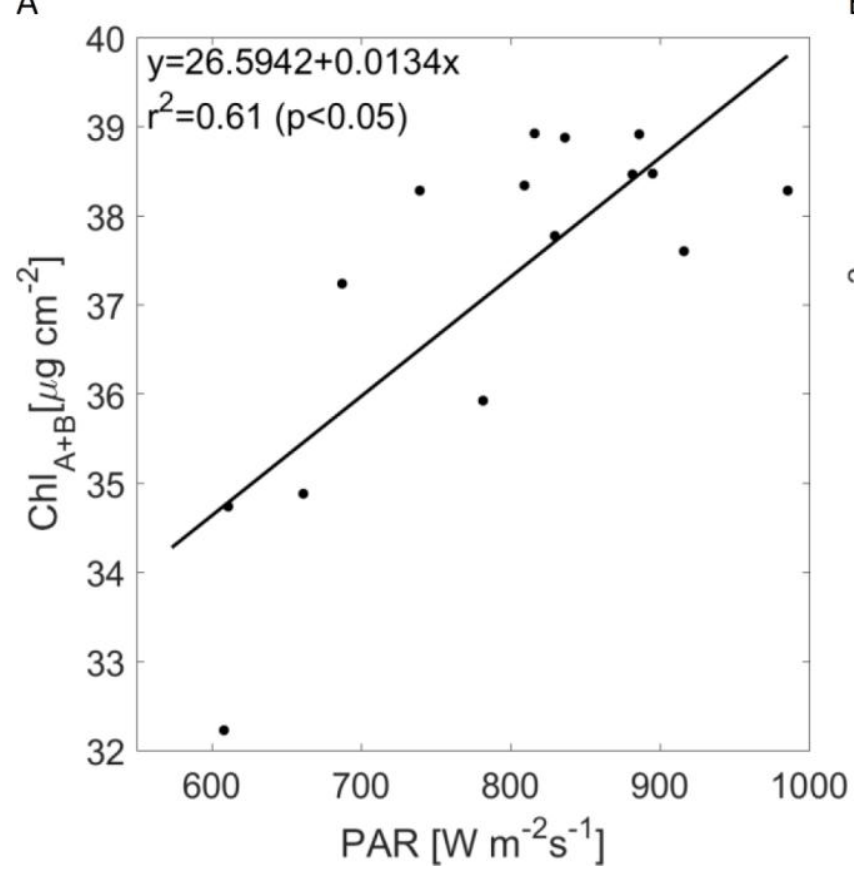

B

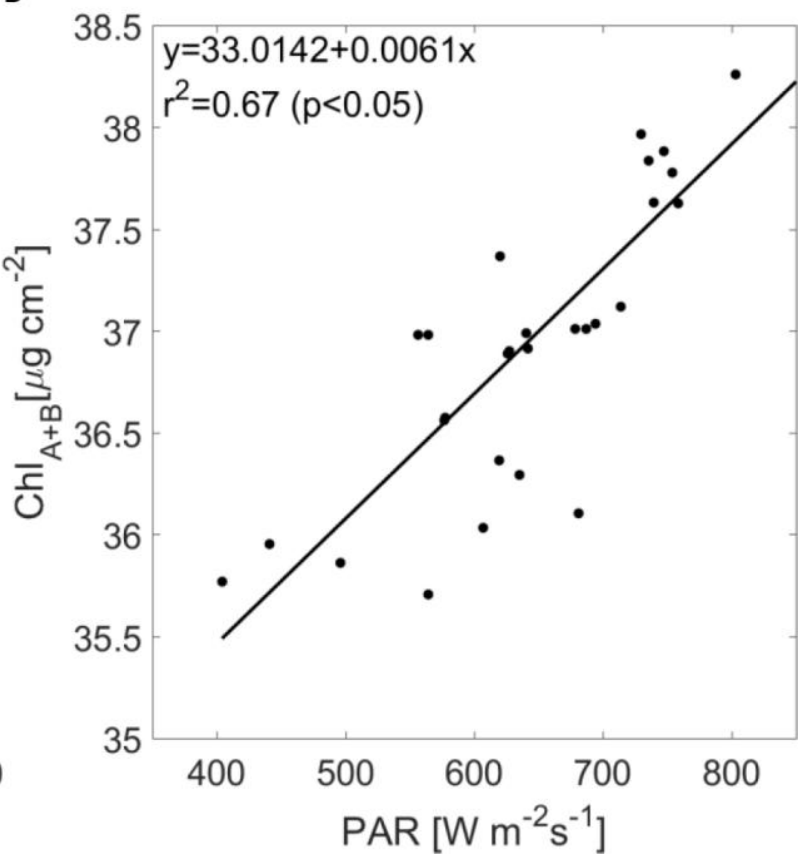

Fig. 9. Relationship with a one-month lag between photosynthetically active radiation (PAR) measured at the top of the eddy flux towers (2000-2006) and corresponding MODIS estimates of $\mathrm{Chl}_{A+B}$ in Manaus (A) and Tapajós (B).

Comparison between monthly averaged NEP and monthly MODIS $\mathrm{Chl}_{\mathrm{A}+\mathrm{B}}$ showed similar seasonal patterns at $\mathrm{k} 34$ (Figure 10A) and k67 (Figure 10B). At Manaus (k34), Chl $\mathrm{A}_{\mathrm{B} B}$ concentrations increased from a minimum average of $31 \mu \mathrm{g} \mathrm{cm}^{-2}$ observed in May to $39 \mu \mathrm{g} \mathrm{cm}$ in August. After that, a steady decline was observed towards the beginning of the next dry season. At Tapajós (k67), mean $\mathrm{Chl}_{\mathrm{A}+\mathrm{B}}$ concentrations showed a minimum value of $32 \mathrm{\mu g} \mathrm{cm}^{-2}$ in May and increased to about $39 \mu \mathrm{gm}^{-2}$ in September. In both sites, the standard deviation decreased from the wet to the dry season. 


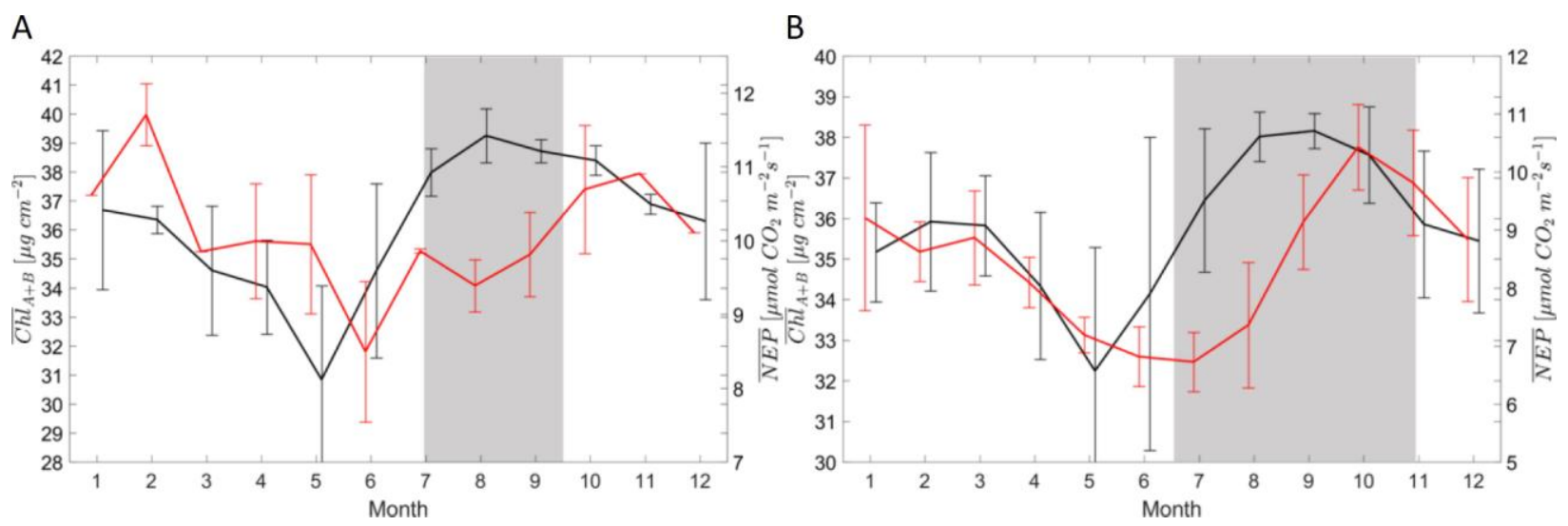

Fig. 10. Seasonality of $\mathrm{Chl}_{A+B}$ (in black, left y-axis) and NEP (in red, right $y$-axis) at the $\mathrm{k} 34(\mathrm{~A})$ and k67 (B) sites. Observations were averaged across multiple years to illustrate the mean seasonal signal. The error bars represent the standard deviations of the monthly mean observations. The gray areas represent the dry season (precipitation $<100 \mathrm{~mm} \mathrm{month}^{-1}$ )

Seasonal changes in $\mathrm{Chl}_{\mathrm{A}+\mathrm{B}}$ were well correlated with new green leaf production published in previous works (Figure 11). $\mathrm{Chl}_{A+B}$ followed new leaf production closely $\left(\mathrm{r}^{2}=0.64\right.$ and 0.59 for k34 and k67, respectively). Prior to month 3, new leaf production increased with chlorophyll concentrations, while between months 3 and 5 no change in new leaf production was observed. $\mathrm{Chl}_{\mathrm{A}+\mathrm{B}}$ declined with a shift of leaf demography towards older leaf area. Starting in month 5, the strong increase in $\mathrm{Chl}_{\mathrm{A}+\mathrm{B}}$ coincided with a strong increase in new leaf production, indicating higher chlorophyll concentration in young and mature leaves than in older ones. 
A

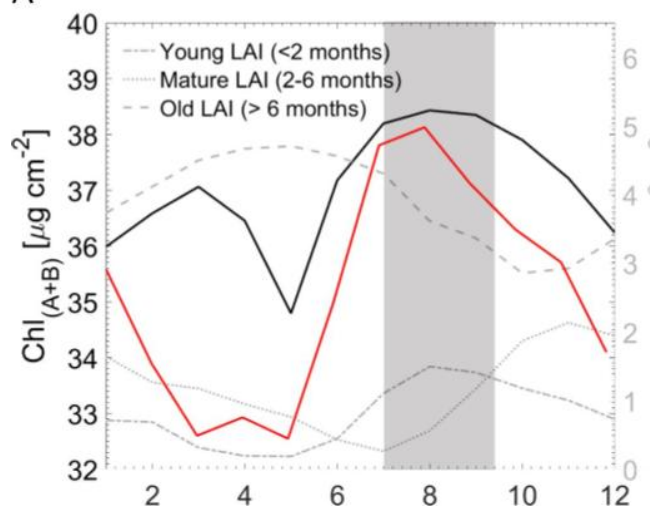

B

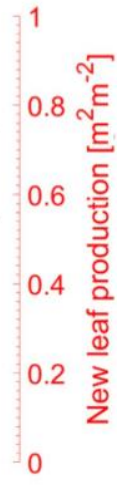

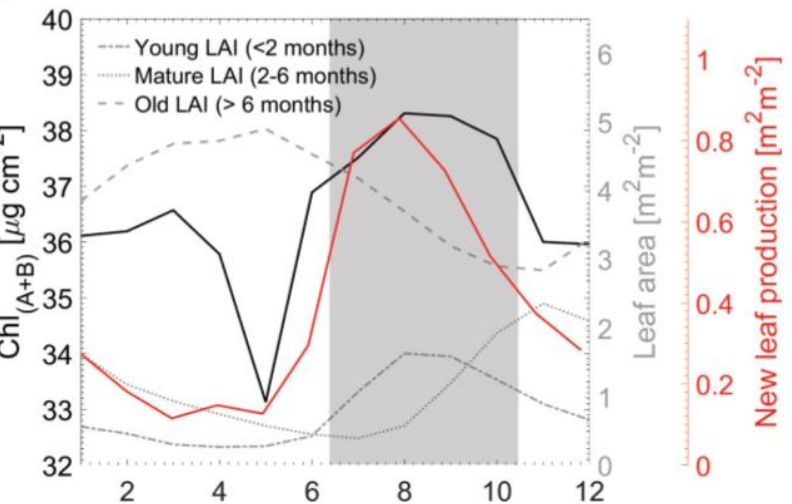

Fig. 11. Seasonal dynamics of $\mathrm{Chl}_{\mathrm{A}+\mathrm{B}}$ concentrations (black, left axis) and vegetation leaf area (gray axis), partitioned in young leaves, mature leaves and old leaves (data from Wu et al., 2016) for the $k 34$ (A) and k67 (B) sites. The figure also shows the seasonal dynamics of new leaf production (in red) $\left(r^{2}=0.64\right.$ and 0.59 , for $k 34$ and $k 67$, respectively). The gray areas represent the dry season (precipitation $<100 \mathrm{~mm} \mathrm{month}^{-1}$ ).

Seasonal patterns observed in $\mathrm{Chl}_{\mathrm{A}+\mathrm{B}}$ were different from vegetation greenness observed by conventional VIs. In Figure 12, EVI and NDVI were derived from the same MODIS MAIAC data product, but were calculated using BRDF normalized (BRFn) observations ( $S Z A=45^{\circ}, V Z A=0^{\circ}$ ). Both vegetation indices showed seasonal variations. However, changes in NDVI were more similar to those observed in $\mathrm{Chl}_{\mathrm{A}+\mathrm{B}}$, but onset and peak of greening occurred earlier, in April. 

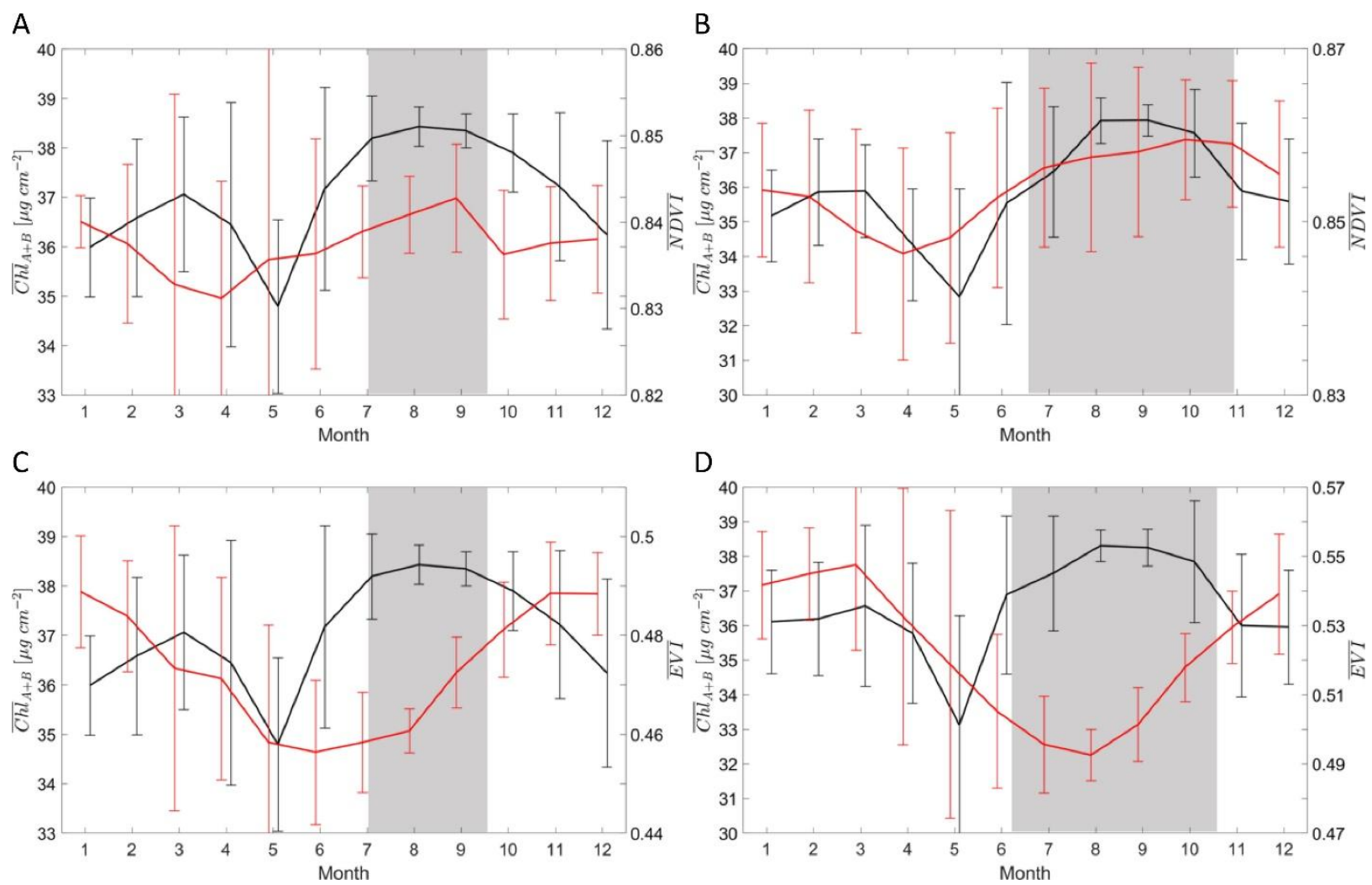

Fig. 12. Seasonal changes in $\mathrm{Chl}_{\mathrm{A}+\mathrm{B}}$ (in black) plotted against NDVI (top line, in red) and EVI (bottom line, in red) for k34 Manaus ( $A$ and $C$ ) and k67 Tapajós ( $B$ and $D)$. The analysis averages years between 2000 and 2015, excluding the extreme drought years of 2005 and 2010. The gray areas represent the dry season (precipitation $<100 \mathrm{~mm} \mathrm{month}{ }^{-1}$ ).

\section{Discussion}

Our unique approach using multi-angle MODIS observations and canopy reflectance model makes two important contributions for the remote sensing of pigment retrievals. The first contribution is to provide a preliminary long-term time series of MODIS (MAIAC)-based chlorophyll estimates over the Amazon. This database can be further refined through robust validation in order to support future canopy chemistry studies provided by the planned 
hyperspectral missions having much better spatial/spectral resolution than MODIS (e.g., EnMAP) but with lower temporal resolution. Despite the need of more samples for robust validation, the convergence of evidences observed during the comparison between chlorophyll estimates and flux tower measurements allow us to observe seasonal changes in the ability of plants to absorb photosynthetically active radiation.

Light absorption of plants is a function of the amount and the efficiency of the photosynthetic surface area. While several studies have reported increases in leaf surface area during the dry season (Hilker et al., 2015; Huete et al., 2006; Myneni et al., 2007), the photosynthetic efficiency of this surface area is largely not accounted for in current photosynthesis models ( $\mathrm{Wu}$ et al., 2016). Absorption efficiency is tightly linked to the concentration of chlorophyll within a leaf (Junker and Ensminger, 2016). Such measures of "leaf efficiency", however, are not easily acquired using VIs. Results of Figure 12 have shown that seasonal patterns of chlorophyll are much more related to changes in the NDVI than the EVI, because the EVI largely dependent on the NIR reflectance (Galvão et al., 2013). Results provided in Figures 5-7 have demonstrated that field measurements of vegetation chlorophyll agreed in rank with ProSAIL estimates from multi-angle MODIS data.

The second contribution of our work is to provide new opportunities for inferring leaf demography and support evidence for it as driver of seasonality in tropical forests. Leaf chlorophyll concentrations are closely linked to leaf age (Doughty and Goulden, 2008). Spatially contiguous estimates of $\mathrm{Chl}_{\mathrm{A}+\mathrm{B}}$ can deliver insights into the proportion of young leaves emerging in a given month. The increase in new leaf production (Figure 11) was consistent with an increase in $\mathrm{ChI}_{\mathrm{A}+\mathrm{B}}$ at both research sites, whereas increase in the proportion of old leaf area 
resulted in a decrease of $\mathrm{Chl}_{A+B}$ observed by MODIS. This different behavior with leaf age is consistent with previous observations concluding that $\mathrm{Chl}_{\mathrm{A}+\mathrm{B}}$ is withdrawn from older leaves in preparation for new leaf production (Hörtensteiner, 2006). As a result, at $1 \mathrm{~km}$ pixel size, changes in leaf chlorophyll concentrations can be interpreted as shifts in the proportion of leafs with higher $\mathrm{Chl}_{A+B}$ versus those with lower $\mathrm{Chl}_{A+B}$ concentrations in addition to changes in leaf area.

The seasonal signal observed from MODIS $\mathrm{Chl}_{\mathrm{A}+\mathrm{B}}$, compared to the high level of species diversity found at both sites, provides evidence of synchronized leaf flushing early during the dry season. Previous results have found that net leaf flushes are asynchronous in regions with short dry seasons and become more synchronous across a west-to-east longitudinal moisture gradient of increasing dry season length. Wu et al. (2016) estimated that the effect of combined new leaf growth shifting canopy composition toward younger, more light-use efficient leaves, explains about $27 \%$ increases in ecosystem productivity. This is consistent with the increase in $\mathrm{Chl}_{\mathrm{A}+\mathrm{B}}$, in response to an increase in tower measured PAR (Figure 9), followed by an increase in net photosynthesis (Figure 10). The findings presented in Figures 8 and 9 allow the conclusion that canopy chlorophyll and leaf area are important drivers of seasonality in tropical forest productivity (Restrepo-Coupe et al., 2013).

The observed increase in chlorophyll together with an increase in PAR (Figure 9) and before an increase in NPP (Figure 10) allows the conclusion that new leaf production drives the seasonal increase in productivity during the dry season months. Therefore, our study supports the view that low radiation during wet season is a growth limiting factor (Brando et al., 2010; Huete et al., 2006; Hutyra et al., 2007; Myneni et al., 2007; Samanta et al., 2012) but suggests 
that the observed increase in productivity during the dry season is preceded by a distinct lightresponse. This light response increases the absorption efficiency of the leaf surface area (Figure 10) in addition to canopy leaf area (Myneni et al., 2007). Taken together, these changes suggest significant seasonal variation in standing canopy photosynthetic capacity (Restrepo-Coupe et al., 2013). Not accounting for these changes may result either in underestimation the seasonal dynamics of tropical vegetation or in overestimation of the effect of sunlight on photosynthesis.

By adjusting the input variables in ProSAIL, the current approach can be applied to other tropical forests of the world. However, for any scenario, robust validation of the chlorophyll estimates is still the greatest challenge due to the need of intensive fieldwork to represent the MODIS footprint size. For instance, our MODIS estimates performed in the $1000 \times 1000 \mathrm{~km}$ area were just supported by a small number of leaves collected around two towers in the Amazon (53 leaves in Tapajós and 203 leaves in Manaus). The strategy of validation can be facilitated with the use of the upcoming hyperspectral EnMAP data (30 $\mathrm{m}$ spatial resolution) and with a network of hyperspectral cameras mounted over other towers in the Amazon. Despite the uncertainties, our seasonal estimates were consistent with flux tower measurements of PAR and NEP.

\section{Conclusions}

We have shown that $\mathrm{Chl}_{\mathrm{A}+\mathrm{B}}$ concentrations over the Amazon can be estimated from multiangle, multi-temporal, multi-spectral MODIS observations through inversion of canopy radiative transfer models at regional scales and over multiple years. The current approach was adapted also to mono-angle hyperspectral observations using hierarchical clustering to reduce the 
number of necessary inversions, and linear spectral unmixing to compute shadow fractions, as demonstrated in the data analysis of the tower-mounted hyperspectral camera. The field chlorophyll measurements were under- and overestimated by ProSAIL using the camera and MODIS data, respectively. Despite the uncertainties and the need of a more robust validation, our results have demonstrated strong seasonal changes in the capacity of leafs to absorb PAR across two tropical forest sites selected to be representative of a broad range of tropical vegetation. This capacity is a function of both, the amount and the chlorophyll concentration within the photosynthetic surface area, and is an important driver of growth performance and vegetation phenology.

We conclude that multi-angle and directional observations from MODIS can help scale vegetation phenology and seasonal controls on ecosystem productivity systematically in space and time. In addition, our long-term chlorophyll estimates comprise an important preliminary database to support future studies in the Amazon using the upcoming EnMAP mission with greater number of bands and better spatial resolution than MODIS but with lower revisit time of the scene. It also contributes to other hyperspectral missions having larger swath width (145 km) such as the planned Hyperspectral Infrared Imager (HyspIRI) (Hochberg et al., 2015).

\section{Acknowledgements}

This work was supported by the Conselho Nacional de Desenvolvimento Científico e Tecnológico (CNPq) (grant number PVE 401025/2014-4); and the GOAmazon project, funded jointly by U.S. Department of Energy (DOE) (DE-SC0008383), Fundação de Amparo à Pesquisa do Estado de São Paulo (FAPESP), and Fundação de Amparo à Pesquisa do Estado do Amazonas 
(FAPEAM) (062.00570/2014). JMM was supported by Coordenação de Aperfeiçoamento de

Pessoal de Nível Superior (CAPES) (12881-13-9). CHA was supported by FAPESP (15/05923-5).

\section{References}

Atkinson, P. M., Dash, J., \& Jeganathan, C. (2011). Amazon vegetation greenness as measured by satellite sensors over the last decade. Geophysical Research Letters, 38(19), L19105. doi:10.1029/2011GL049118

Bi, J., Knyazikhin, Y., Choi, S., Park, T., Barichivich, J., Ciais, P., Fu, R., Ganguly, S., Hall, F., Hilker, T., Huete, A., Jones, M., Kimball, J., Lyapustin, A. I., Mõttus, M., Nemani, R. R., Piao, S., ... Myneni, R. B. (2015). Sunlight mediated seasonality in canopy structure and photosynthetic activity of Amazonian rainforests. Environmental Research Letters, 10(6), 064014. doi:10.1088/1748-9326/10/6/064014

Brando, P. M., Goetz, S. J., Baccini, A., Nepstad, D. C., Beck, P. S. a, \& Christman, M. C. (2010). Seasonal and interannual variability of climate and vegetation indices across the Amazon. Proceedings of the National Academy of Sciences of the United States of America, 107(33), 14685-90. doi:10.1073/pnas.0908741107

Cleland, E. E., Chuine, I., Menzel, A., Mooney, H. A., \& Schwartz, M. D. (2007). Shifting plant phenology in response to global change. Trends in Ecology \& Evolution, 22(7), 357-65. doi:10.1016/j.tree.2007.04.003

Costa, M. H., \& Cohen, W. B. (2013). LBA-ECO CD-15 LAl and Productivity Data, km 67, Tapajos National Forest: 2003-2004. National Laboratory Distributed Active Archive Center for Biogeochemical Dynamics. doi:10.3334/ORNLDAAC/1167

Doughty, C. E., \& Goulden, M. L. (2008). Seasonal patterns of tropical forest leaf area index and CO 2 exchange. Journal of Geophysical Research, 113, G00B06. doi:10.1029/2007JG000590

Galvão, L. S., Breunig, F. M. F. M., Santos, J. R. dos, Moura, Y. M. de (2013). View-illumination effects on hyperspectral vegetation indices in the Amazonian tropical forest. International Journal of Applied Earth Observation and Geoinformation, 21(1), 291-300. doi:10.1016/j.jag.2012.07.005

Gruninger, J. H., Ratkowski, A. J., \& Hoke, M. L. (2004). The sequential maximum angle convex cone (SMACC) endmember model. In S. S. Shen \& P. E. Lewis (Eds.), Defense and Security (pp. 1-14). International Society for Optics and Photonics. doi:10.1117/12.543794

Guan, K., Pan, M., Li, H., Wolf, A., Wu, J., Medvigy, D., Caylor, K. K., Sheffield, J., Wood, E. F., Malhi, Y., Liang, M., Kimball, J. S., Saleska, S. R., Berry, J., Joiner, J., \& Lyapustin, A. I. (2015). Photosynthetic seasonality of global tropical forests constrained by hydroclimate. Nature Geoscience, advance on. doi:10.1038/ngeo2382

Guanter, L., Kaufmann, H., Segl, K., Foerster, S., Rogass, C., Chabrillat, S., Küster, T., et al. (2015). The EnMAP spaceborne imaging spectroscopy mission for Earth observation. Remote 
Sensing, 7, 8830-8857.

Hilker, T., Lyapustin, A. I., Hall, F. G., Myneni, R., Knyazikhin, Y., Wang, Y., Tucker, C. J., \& Sellers, P. J. (2015). On the measurability of change in Amazon vegetation from MODIS. Remote Sensing of Environment, 166, 233-242. doi:10.1016/j.rse.2015.05.020

Hilker, T., Lyapustin, A. I., Tucker, C. J., Sellers, P. J., Hall, F. G., \& Wang, Y. (2012). Remote sensing of tropical ecosystems: Atmospheric correction and cloud masking matter. Remote Sensing of Environment, 127, 370-384. doi:10.1016/j.rse.2012.08.035

Hochberg, E. J., Roberts, D. A., Dennison, P. E., \& Hulley, G. C. (2015). Special issue on the Hyperspectral Infrared Imager (HyspIRI): emerging science in terrestrial and aquatic ecology, radiation balance and hazards. Remote Sensing of Environment, 167, 1-5.

Hörtensteiner, S. (2006). Chorophyll degradation during senescence. Annual Review of Plant Biology, 57(1), 55-77. doi:10.1146/annurev.arplant.57.032905.105212

Huete, A. R., Didan, K., Shimabukuro, Y. E., Ratana, P., Saleska, S. R., Hutyra, L. R., Yang, W., Nemani, R. R., \& Myneni, R. (2006). Amazon rainforests green-up with sunlight in dry season. Geophysical Research Letters, 33(6), L06405. doi:10.1029/2005GL025583

Hutyra, L. R., Munger, J. W., Saleska, S. R., Gottlieb, E., Daube, B. C., Dunn, A. L., Amaral, D. F., de Camargo, P. B., \& Wofsy, S. C. (2007). Seasonal controls on the exchange of carbon and water in an Amazonian rain forest. Journal of Geophysical Research, 112(G3), G03008. doi:10.1029/2006JG000365

Jacquemoud, S., Verhoef, W., Baret, F., Bacour, C., Zarco-Tejada, P. J., Asner, G. P., François, C., \& Ustin, S. L. (2009). PROSPECT+ SAIL models: a review of use for vegetation characterization. Remote Sensing of Environment, 113, S56-S66. doi:10.1016/j.rse.2008.01.026

Junker, L. V., \& Ensminger, I. (2016). Relationship between leaf optical properties, chlorophyll fluorescence and pigment changes in senescing Acer saccharum leaves. Tree Physiology, tpv148. doi:10.1093/treephys/tpv148

Lichtenthaler, H. (1987). Chlorophyll and carotenoids: pigments of photosynthetic biomembranes. METHODS IN ENZYMOLOGY, 148, 350-382. Retrieved from http://en.journals.sid.ir/ViewPaper.aspx?ID=113378

Lyapustin, A. I., Wang, Y., Laszlo, I., Hilker, T., G.Hall, F., Sellers, P. J., Tucker, C. J., \& Korkin, S. V. (2012). Multi-Angle Implementation of Atmospheric Correction for MODIS (MAIAC). Part 3: Atmospheric Correction. Remote Sensing of Environment, 127, 385-393. doi:10.1016/j.rse.2012.09.002

Moré, J., Garbow, B., \& Hillstrom, K. (1980). User guide for MINPACK-1. Retrieved from http://cds.cern.ch/record/126569

Morton, D. C., Nagol, J., Carabajal, C. C., Rosette, J., Palace, M., Cook, B. D., Vermote, E. F., Harding, D. J., \& North, P. R. J. (2014). Amazon forests maintain consistent canopy structure and greenness during the dry season. Nature, doi:10.103(7487), 221-4. doi:10.1038/nature13006 
Moura, Y. M. de, Hilker, T., Lyapustin, A. I., Galvão, L. S., dos Santos, J. R., Anderson, L. O., de Sousa, C. H. R., \& Arai, E. (2015). Seasonality and drought effects of Amazonian forests observed from multi-angle satellite data. Remote Sensing of Environment, 171, 278-290. doi:10.1016/j.rse.2015.10.015

Myneni, R. B., Yang, W., Nemani, R. R., Huete, A. R., Dickinson, R. E., Knyazikhin, Y., Didan, K., Fu, R., Negrón Juárez, R. I., Saatchi, S. S., Hashimoto, H., Ichii, K., Shabanov, N. V, Tan, B., Ratana, P., Privette, J. L., Morisette, J. T., ... Salomonson, V. V. (2007). Large seasonal swings in leaf area of Amazon rainforests. Proceedings of the National Academy of Sciences of the United States of America, 104(12), 4820-3. doi:10.1073/pnas.0611338104

Nepstad, D. C., de Carvalho, C. R., Davidson, E. A., Jipp, P. H., Lefebvre, P. A., Negreiros, G. H., da Silva, E. D., Stone, T. A., Trumbore, S. E., \& Vieira, S. (1994). The role of deep roots in the hydrological and carbon cycles of Amazonian forests and pastures. Nature, 372(6507), 666-669. doi:10.1038/372666a0

Ozanne, C. M. P., Anhuf, D., Boulter, S. L., Keller, M., Kitching, R. L., Ko, C., Meinzer, F. C., \& Mitchell, a W. (2003). Biodiversity Meets the Atmosphere: A Global View of Forest Canopies. Science, 301(July), 183-186. doi:10.1126/science.1084507

Restrepo-Coupe, N., da Rocha, H. R., Hutyra, L. R., da Araujo, A. C., Borma, L. S., Christoffersen, B., Cabral, O. M. R., de Camargo, P. B., Cardoso, F. L., da Costa, A. C. L., Fitzjarrald, D. R., Goulden, M. L., Kruijt, B., Maia, J. M. F., Malhi, Y. S., Manzi, A. O., Miller, S. D., ... Saleska, S. R. (2013). What drives the seasonality of photosynthesis across the Amazon basin? A cross-site analysis of eddy flux tower measurements from the Brasil flux network. Agricultural and Forest Meteorology, 182-183, 128-144. doi:10.1016/j.agrformet.2013.04.031

Roujean, J. J.-L., Leroy, M., \& Deschamps, P.-Y. (1992). A bidirectional reflectance model of the Earth's surface for the correction of remote sensing data. Journal of Geophysical Research, 97(D18), 20455-20468. doi:10.1029/92JD01411

Saleska, S. R., Miller, S. D., Matross, D. M., Goulden, M. L., Wofsy, S. C., da Rocha, H. R., de Camargo, P. B., Crill, P., Daube, B. C., de Freitas, H. C., Hutyra, L., Keller, M., Kirchhoff, V., Menton, M., Munger, J. W., Pyle, E. H., Rice, A. H., \& Silva, H. (2003). Carbon in Amazon forests: unexpected seasonal fluxes and disturbance-induced losses. Science (New York, N.Y.), 302(5650), 1554-7. doi:10.1126/science.1091165

Samanta, A., Ganguly, S., Vermote, E., Nemani, R. R., \& Myneni, R. B. (2012a). Why Is Remote Sensing of Amazon Forest Greenness So Challenging? Earth Interactions, 16(7), 1-14. doi:10.1175/2012EI440.1

Sellers, P. J., Randall, D. A., Collatz, G. J., Berry, J. A., Field, C. B., Dazlich, D. A., Zhang, C., Collelo, G. D., \& Bounoua, L. (1996). A Revised Land Surface Parameterization (SiB2) for Atmospheric GCMS. Part I: Model Formulation. Journal of Climate, 9(4), 676-705. doi:10.1175/1520-0442(1996)009<0676:ARLSPF>2.0.CO;2

Wu, J., Albert, L. P., Lopes, A. P., Restrepo-Coupe, N., Hayek, M., Wiedemann, K. T., Guan, K., Stark, S. C., Christoffersen, B., Prohaska, N., Tavares, J. V., Marostica, S., Kobayashi, H., Ferreira, M. L., Campos, K. S., Silva, R. Da, Brando, P. M., ... Saleska, S. R. (2016). Leaf 
development and demography explain photosynthetic seasonality in Amazon evergreen forests. Science, 351(6276), 972-977. doi:10.1126/science.aad5068

Zhang, Y., Tan, Z., Song, Q., Yu, G., \& Sun, X. (2010). Respiration controls the unexpected seasonal pattern of carbon flux in an Asian tropical rain forest. Atmospheric Environment, 44(32), 3886-3893. doi:10.1016/j.atmosenv.2010.07.027

Zhou, L., Tian, Y., Myneni, R. B., Ciais, P., Saatchi, S., Liu, Y. Y., Piao, S., Chen, H., Vermote, E. F., Song, C., \& Hwang, T. (2014). Widespread decline of Congo rainforest greenness in the past decade. Nature, 509(7498), 86-90. doi:10.1038/nature13265 


\section{Multi-angle Amazon Physiology and Structure (MAPS)}
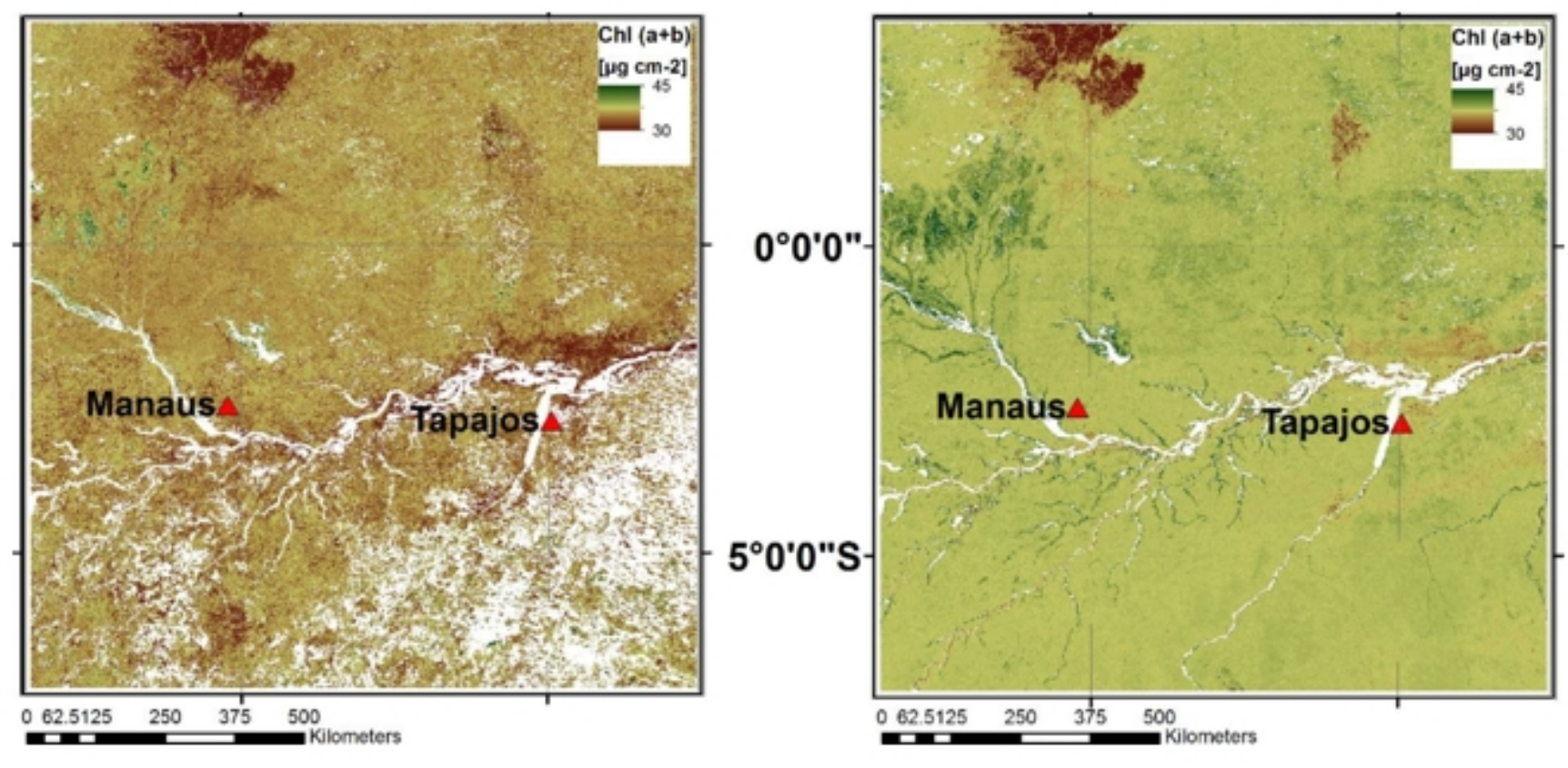

MODIS BRDF and tower hyperspectral data
ProSAIL Canopy Reflectance Model
Chlorophyll estimates 